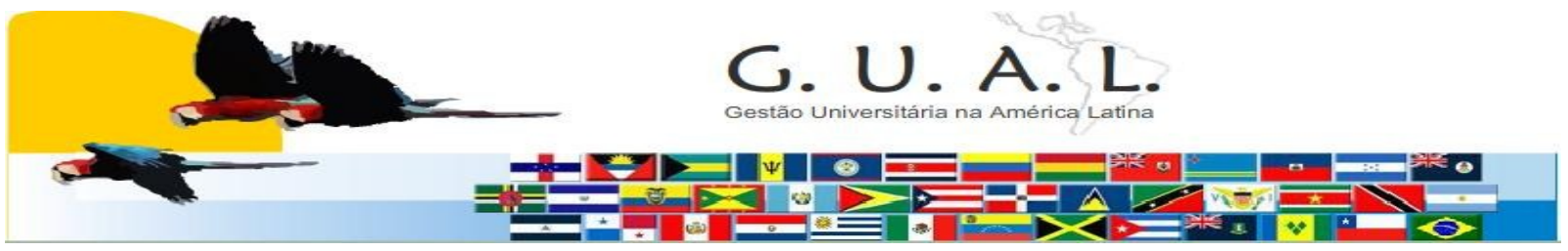

ISSN 1983-4535

\title{
DIAGNÓSTICO E ANÁLISE DO MAPA ESTRATÉGICO DE UMA CORPORAÇÃO RELIGIOSA COM OBJETIVOS EDUCACIONAIS: ESTUDO DE CASO
}

\author{
Jorge Gaio, Bacharel \\ Pontifícia Universidade Católica do Paraná - PUC/PR \\ irjorge@marista.org.br \\ Luiz Carlos Duclós, Doutor \\ Pontifícia Universidade Católica do Paraná-PUC/PR \\ luiz.duclos@pucpr.br
}

\begin{abstract}
RESUMO
As corporações educacionais internacionais têm ampliado a atuação no cenário nacional, pressionando a melhoria das estratégias de desempenho e a estrutura das organizações. $\mathrm{O}$ objetivo deste estudo de caso de natureza exploratória, qualitativa e descritiva é diagnosticar a coerência do Mapa Estratégico em uma Corporação Religiosa com objetivos educacionais, com fins não econômicos, nas quatro perspectivas do Balanced Scorecard - BSC, tendo como base o planejamento estratégico de 2010 a 2022. Inicialmente foi realizada uma revisão de literatura contemplando os principais aspectos do BSC sobre a tradução e a avaliação da estratégia. O BSC é um importante instrumento de alinhamento entre processos e estratégias, na medida em que associa concretamente os fatores impulsionadores do desempenho com medições de resultados. Usando o Mapa Estratégico da Corporação Religiosa foi diagnosticado a coerência do mesmo no nível estratégico da organização e se a tradução e os indicadores da estratégia são percebidos pelos gestores da área Corporativa, utilizando entrevista com questionário semiestruturado. Os resultados obtidos sinalizam relativo balanceamento e alinhamento dos objetivos estratégico, baixa relação de causalidade do mapa, comunicação estratégica insuficiente e fragmentada. Os indicadores de desempenho estão referenciados mais a meritocracia do que ao Mapa Estratégico e que retrata uma visão de curto prazo em detrimento do longo prazo. Entretanto existem evidências de melhoria do gerenciamento e desempenho estratégico.
\end{abstract}

Palavras-chave: Corporação religiosa. Mapa estratégico. Indicadores de desempenho. 


\section{DIAGNÓSTICO E ANÁLISE DO MAPA ESTRATÉGICO DE UMA CORPORAÇÃO RELIGIOSA COM OBJETIVOS EDUCACIONAIS: ESTUDO DE CASO}

\section{INTRODUÇÃO}

As organizações contemporâneas estão se deparando com ambientes extremamente dinâmicos, provocando alterações profundas no modo de serem gerenciadas. Nos últimos anos, a proliferação de grandes grupos privados estrangeiros tem impactado na educação pública e privada do país. As organizações com fins não econômicos que atuam no campo da educação estão neste contexto sujeitas a todas as intempéries e oportunidades dos mercados globalizados.

Ocorre algo similar com as Corporações Religiosas que tradicionalmente contribuíram efetivamente para o acesso e o desenvolvimento da educação no país estão sistematicamente perdendo espaço na contemporaneidade para empresas mais arrojadas, flexíveis, profissionalizadas e com alto capital de investimento.

A concorrência tem se apresentado mais agressiva na última década, fazendo com que algumas Corporações Religiosas se profissionalizem, melhorem sua governança, alterem a estrutura de gestão, aumentem seu ganho de escala, atuem em rede, fortaleçam a qualidades dos serviços prestados, estabeleçam o alinhamento estratégico e efetivamente proporcionem desempenho superior. Muitas destas organizações, recentemente, começaram a utilizar ferramentas de gestão e boas práticas, sejam provenientes da área empresarial, sejam ajustadas as suas especificidades.

Vieira (2007, p. 24-25) destaca que as organizações que pretendem expandir e consolidar no setor, seja por meio de vendas a grupos estrangeiros, pela abertura de capital, fusões ou formação de conglomerados, devem intensificar a preocupação com a transparência e profissionalização dos sistemas de gestão. Segundo Avancini (2010), somente em julho e agosto de 2010, foram concretizados quatro grandes negócios: a Abril Educação comprou o Anglo; o fundo de investimentos BR Investimentos comprou parte da Abril Educação, numa transação na faixa de R 200 milhões; a britânica Pearson, assumiu o controle do Sistema Educacional Brasileiro (SEB), proprietário do COC, Pueri Domus e Dom Bosco; a Buffalo Investimentos adquiriu a operação de apostilas e treinamento docente do Universitário; por fim, a Kroton Educacional adquiriu o Grupo Iuni, por R \$ 600 milhões.

O aporte de capital internacional e a concentração em grandes grupos têm aumentado a concorrência, pressionado a melhoria da qualidade na prestação de serviços, a carteira de

Rev. GUAL., Florianópolis, v.4, n. 2, p.182-204, mai/ago. 2011 
portfólio, a estruturação das áreas corporativas, de apoio e unidades de negócio e, a qualificação da gestão estratégica das corporações que atuam no campo da educação.

O presente trabalho tem por objetivo diagnosticar a coerência do Mapa Estratégico da Corporação Religiosa, a partir do olhar dos gestores estratégicos da área de apoio, nas quatro perspectivas do BSC, tendo como base o planejamento estratégico de 2010 a 2022 . A organização é de fins não econômicos e possui diversas unidades de negócio, dentre elas educação, saúde, comunicação e solidariedade. O estudo de caso é de natureza exploratória, qualitativa, descritiva e a amostra é não probabilística intencional, utilizando dados primários e secundários.

\section{ELEMENTOS DO BSC}

Esta seção estabelece uma revisão conceitual dos termos relevantes para o presente estudo. Apresenta os fundamentos do BSC e suas quatro perspectivas, e estabelece o conceito de estratégia, mapa estratégico e indicadores.

\subsection{Fundamentos do BSC}

O BSC, segundo Kaplan e Norton (2001), é uma ferramenta da gestão que possibilita a comunicação da estratégia, a avaliação do desempenho organizacional e a promoção do alinhamento estratégico, desde as ações e resultados de uma organização com seus objetivos, favorecendo o desempenho pretendido e o alcance dos objetivos organizacionais. Para Kaplan e Norton (1997, p. 39) o BSC é "um mecanismo para a implementação da estratégia, não para sua formulação".

Para Kaplan e Norton (2001), o mapa estratégico explicita a hipótese da estratégia, descrevendo o processo de transformação dos ativos intangíveis em resultados tangíveis para os clientes, e por consequência os resultados financeiros. Segundo Kaplan e Norton (1997), o BSC traduz a missão e a estratégia em objetivos e medidas. Tal instrumento auxilia os gestores na condução de seus negócios de forma organizada e sistêmica. O BSC é um catalisador por que permite a integração entre áreas, sob o mesmo entendimento da estratégia.

Costa (2006) salienta que com o passar dos anos, o BSC, que havia sido concebido como um sistema de mensuração de desempenho, havia se transformado em sistema de comunicação e alinhamento da estratégia da organização, passou a ser explorado como um 


\section{DIAGNÓSTICO E ANÁLISE DO MAPA ESTRATÉGICO DE UMA CORPORAÇÃO RELIGIOSA COM OBJETIVOS EDUCACIONAIS: ESTUDO DE CASO}

sistema de gerenciamento da estratégia. O BSC repensa temas antigos presentes na literatura de contabilidade e controle gerencial, chamando atenção para pontos que estavam esquecidos ou mal compreendidos e articulando pontos vitais - estratégia e operação - indicando, como a estratégia da empresa será cumprida.

Kaplan e Norton (1997) destacam que o BSC possibilita o equilíbrio de vários aspectos, por exemplo: entre objetivos de curto e de longo prazo, entre indicadores financeiros e não financeiros, entre prospectivos e perspectivos, entre indicadores de resultados ocorridos e de tendências de desempenho futuro. O BSC propicia um equilíbrio entre medidas objetivas, ligadas a resultados facilmente quantificáveis, e subjetivas, que tratam de vetores que vão influenciar resultados futuros e precisam ser medidos no presente.

Frente aos novos ambientes de mercado, em que a imprevisibilidade e dinamicidade dos ambientes afetam mais rapidamente as organizações, o uso exclusivo de aspectos meramente financeiros para averiguar o desempenho passado da organização não é suficiente. Segundo Kaplan e Norton (1997, p. 2), com o advento da informação e do conhecimento, apresentam que "as empresas não conseguem mais obter vantagens competitivas sustentáveis apenas com a rápida alocação de novas tecnologias e ativos físicos, e com a excelência da gestão eficaz dos ativos e passivos financeiros".

A gestão estratégica para Kaplan e Norton (1997) se traduz em um processo contínuo e adaptativo que estabelece a missão, os objetivos e metas, as estratégias e ações para atingir cenário proposto, em determinado tempo, interagindo com o ambiente. Para Costa (2006, p. 11), o BSC trata das informações chaves para gerenciar o cumprimento da estratégia da empresa e dos processos gerenciais que promovem o alinhamento estratégico necessário.

Para Caiuby e Luciano (2005, p. 64), os processos impactam na estratégia, nos clientes e os processos interfuncionais, podem ser considerados fatores críticos de sucesso. Tais fatores são os processos de maior relevância para criação e proposição de valor da organização, que devem ser priorizados e apresentados numa relação de causa e efeito. Processo é um conjunto limitado de atividades inter-relacionadas, compostas de entradas e saídas, organizadas no espaço e no tempo, por meio da combinação de pessoas e métodos.

Kaplan e Norton (1997, p. 9) destacam que as empresas preocupadas com a inovação estão utilizando o BSC como um sistema de gestão estratégico, capaz de viabilizar processos gerenciais críticos: - esclarecer e traduzir a visão e a estratégia; - comunicar e associar 
objetivos e medidas estratégicas; - planejar, estabelecer metas e alinhar iniciativas estratégicas e, - melhorar o feedback e o aprendizado estratégico. O BSC fornece um referencial para descrever e comunicar a estratégia de maneira coerente nos diversos níveis organizacionais.

Portanto, o BSC cria uma estrutura, uma linguagem, para comunicar a missão e a estratégia, e utiliza indicadores para informar os colaboradores sobre os vetores do sucesso atual e futuro. A ferramenta traduz a visão e a estratégia da organização em objetivos e medidas tangíveis. Ao articularem os resultados desejados pela empresa com os vetores desses resultados, os executivos esperam canalizar as energias, as habilidades e os conhecimentos específicos das pessoas na empresa inteira, para alcançar as metas de longo prazo. Por fim, assegura o desenho conjunto de todas as áreas relevante da organização e na identificação dos encadeamentos de ações que possibilitam o desempenho sustentável.

\subsection{Estratégia e Mapas Estratégicos}

Rampersad (2004, p. 44) destaca que a missão envolve a identidade da organização e indica sua razão de ser. Já a visão organizacional representa o sonho, o compartilhamento de uma imagem futura almejada e viável, além de explicitar a trajetória necessária para seu alcance. São os fatores críticos de sucesso que indicam sua singularidade, aquilo que a diferencia das demais, em busca da excelência.

Andrews (1971, p. 79) define estratégia como um conjunto de objetivos, finalidades, metas, diretrizes essenciais e os planos para atingi-las, assim expressa o que a empresa deseja ser e o que ela é em relação ao cliente e a sociedade. Portanto, a estratégia é a maneira pela qual a organização procura distinguir-se da concorrência, estabelecendo vantagem competitiva. Wright, Kroll e Parnell (2000, p. 45) coadunam ao afirmarem estratégia como "planos da alta administração para alcançar resultados consistentes com a missão e os objetivos gerais da organização".

Porter (1999, p. 33) enfatiza que a estratégia "é criar uma posição exclusiva e valiosa, envolvendo um diferente conjunto de atividades". Isso se torna possível, quando há alinhamento entre as atividades internas e a proposição de valor para as partes interessadas. Furlan (2007, p. 31) diz que a finalidade da estratégia "é estabelecer quais serão os caminhos, os programas de ação que deverão ser seguidos pela organização para que se alcancem os objetivos e as metas estabelecidas". Já para Hofer e Schender (1978), estratégia é um processo 


\section{DIAGNÓSTICO E ANÁLISE DO MAPA ESTRATÉGICO DE UMA CORPORAÇÃO RELIGIOSA COM OBJETIVOS EDUCACIONAIS: ESTUDO DE CASO}

de alocação de recursos e interações ambientais presentes e futuras que sinaliza como a organização atingirá seus objetivos.

Kaplan e Norton $(1997$, p. 30; 155) definem estratégia como um "conjunto de hipóteses sobre causa e efeitos", ou seja, uma relação de alternativas do tipo "se... então...". E ainda, segundo os autores (1997, p. 38) a estratégia, vinculada ao posicionamento competitivo é uma "escolha de segmentos de mercado e clientes que as unidades de negócio pretendem seguir, identificando os processos criativos nos quais devem atingir a excelência".

Wright, Kroll e Parnell (2000) destacam a alocação hierárquica da estratégia na estrutura organizacional pode estar configurada em três níveis: i) corporativa - a estratégia define o conjunto de negócios da organização; ii) de negócio - estratégia foca o modo de competir num setor ou segmento produto/mercado, iii) funcional - estratégia foca na maximização da produtividade dos recursos. $\mathrm{Na}$ verdade, todos os três níveis estão intimamente relacionados. Neste sentido, segundo Mintzberg e Quinn (1991), a estratégia distribui-se nos diversos níveis da organização. Neste estudo opta-se por aprofundar a estratégia corporativa.

Porter (1999, p. 237) define a estratégia corporativa como o "plano geral para uma empresa diversificada que trata de duas questões diferentes: em que negócios a empresa deve competir e como a sede corporativa deve gerenciar o conjunto de unidades de negócios". O autor explicita que o todo corporativo é maior que a soma das partes. Wright, Kroll e Parnell (2000, p. 127) definem estratégia corporativa como a "estratégia que a alta administração formula para toda a empresa".

Para Duclós e Santana (2010, p. 86; 151), o mapa estratégico nas organizações mais complexas, é primeiramente elaborado pela corporação e depois desdobrado para unidades de negócio. No BSC, o desdobramento integrado é que garante o alinhamento e a sinergia para a alocação eficaz dos recursos disponíveis na organização, e não mapas estratégicos isolados.

Para Duclós e Santana (2010) a estratégia é o caminho que materializa a visão e precisa ser traduzida para ser compreendida por todas as pessoas da organização. A estrutura, os processos de negócio e o comportamento das pessoas devem seguir a estratégia. Já os objetivos estratégicos são decorrentes dos fatores críticos de sucesso, estruturados numa relação de causa-efeito, partindo dos objetivos relacionados a ativos intangíveis e culminando com objetivos estratégicos relacionados com ativos tangíveis. O mapa estratégico descreve o 
como a organização cria valor e traduz de maneira clara o raciocínio lógico de causa-efeito entre os objetivos estratégicos distribuídos nas diversas perspectivas, as quais podem ser distintas, segundo a estratégia de cada organização. O tema estratégico é um recorte vertical no mapa estratégico, incluindo os componentes do BSC, a partir dos fatores críticos levantados.

Caiuby e Luciano (2005, p. 66) destacam que o alinhamento dos processos com a estratégia é essencial para o desempenho da organização. Os fatores críticos de sucesso são uma ferramenta para suportar o processo de detalhamento e tradução dos objetivos estratégicos em termos mais operacionais. Cabe relacionar cada um dos processos críticos, com os objetivos estratégicos e monitorar seu desempenho, identificando a prontidão de tais processos. Rampersad (2004, p. 112) enfatiza que os objetivos estratégicos devem ser mensuráveis, abertos as influências, aceitáveis pelas pessoas da organização, em alinhamento com o horizonte traçado e compartilhado, com a cultura de negócio e com disponibilidade de conhecimento e habilidades para sua realização.

Costa (2006, p. 11) desta que o mapa estratégico serve para contar a história da estratégia da organização, o qual deve ser comunicado a todos os níveis da empresa, estar vinculado ao sistema de recompensas e constituir-se na referencial fundamental para as reuniões e decisões dos diferentes níveis de gestores. O mapa estratégico auxilia a alta administração na priorização e no monitoramento do cumprimento da estratégia de maneira sucinta. Mapa estratégico é uma representação simplificada da realidade.

Kallás e Coutinho $(2005$, p. 8) descrevem que os mapas estratégicos proporcionam a transformação de idéias, causas, lutas em projetos e ações concretos que possam a ser monitorados com indicadores de resultado. Para Kaplan e Norton (2004, p. 41), o mapa estratégico é composto por objetivos, metas, indicadores e iniciativas estratégicas, pertinentes a qualquer sistema de gestão e controle. O BSC utiliza um conjunto de indicadores para mensurar o desempenho conseguido em cada um dos objetivos descritos em cada uma das perspectivas. É comum, o BSC utilizar linguagem gráfica, em que o mapeamento de um processo é a representação simplificada da relação de atividades do processo e ajuda na comunicação da organização. 


\section{DIAGNÓSTICO E ANÁLISE DO MAPA ESTRATÉGICO DE UMA CORPORAÇÃO RELIGIOSA COM OBJETIVOS EDUCACIONAIS: ESTUDO DE CASO}

\subsection{Perspectivas do BSC}

Segundo Costa (2006) ao desenhar o mapa estratégico da empresa é preciso identificar os fatores críticos de sucesso. Tais fatores estão atrelados ao valor a ser criado e entregue aos clientes, ao alinhamento dos processos da organização e aos investimentos e habilidades da mesma. Assim, cada perspectiva deve expressar o tipo de decisão estratégica que será tomada, respeitando a posição de valor e cada fase em que o negócio se encontra. Kaplan e Norton (1997, p. 25-29) destacam que o BSC está ancorado sob quatro perspectivas que impulsionam o desempenho para o futuro de maneira mais integrada:

Perspectiva Financeira - Esta perspectiva avalia o desempenho da organização em gerar resultados que satisfaçam seus acionistas e garantam sua sobrevivência e crescimento sustentável. Em geral, esse êxito é medido pela sua lucratividade (ROI - Return on investment, EBITDA em relação à receita ou dívida, EVA - Economic Added Value, etc.), pelo crescimento do negócio e pelo incremento do valor ao acionista. Em se tratando de organizações sem fins lucrativos, o objetivo prioritário é cumprir a missão, assim, os recursos financeiros exercem o papel de provento e de restrição para execução da missão.

Perspectiva dos Clientes e da Sociedade - O desempenho é avaliado com base na capacidade de construir um relacionamento duradouro e rentável com seus clientes. Conhecer os clientes e ouvi-los é fundamental para uma estratégia organizacional que tenha como um de seus principais focos a satisfação, imagem, reputação, fidelidade, retenção e captação de clientes. Em organizações sem fins lucrativos, os clientes são compostos pelos usuários, contribuintes, os representantes legais que tomam as decisões e os atores públicos.

Perspectiva dos Processos Internos - A organização deve agir na sua cadeia de processos interligados, e não apenas de modo isolado. O BSC oferece excelente oportunidade de organizar os processos: relacionados à gestão operacional, à inovação, à gestão de clientes, regulatórios e sociais. Devem-se centrar esforços na inovação, operações e pós-venda.

Perspectiva do Aprendizado e Crescimento - Pressionados pelo ambiente interno e ou externo, as organizações precisam constantemente realizar mudanças, para tal, utilizam-se: das capacidades e das competências das pessoas em apreender e inovar, composto pelo capital humano com condições de reforçar a estratégia; - dos sistemas de informação, caracterizado pelo capital da informação, dados e ferramentas de rede, que favorecem a implementação da estratégia; - e a estrutura e procedimentos organizacionais, que abrange o capital 
organizacional e cultural alinhados à estratégia. Evidencia-se a necessidade da retenção, da satisfação e da produtividade dos colaboradores.

Kaplan e Norton (1997) criam uma estrutura em que cada perspectiva descreve objetivos que derivam da missão, visão, valores e fatores críticos de sucesso, dos quais, decorrem indicadores, que mostra o quanto e como está sendo cumprido determinado objetivo.

\subsection{Indicadores}

Para Takashina e Flores (1996), os indicadores são formas tangíveis e intangíveis utilizados por organizações para a melhoria e o controle de qualidade e desempenho dos processos, dos produtos e dos serviços. Os indicadores devem estar sempre associados às áreas do negócio, em consonância com os objetivos estratégicos e intimamente ligados a qualidade da prestação de serviço e observáveis pelo cliente, em vista a excelência. A formulação de indicadores precisa de uma metodologia consistente, capaz de observar: a relevância; a simplicidade e a clareza; a abrangência; a rastreabilidade; a comparabilidade; a rapidez em ser gerado; a confiabilidade e o baixo custo de obtenção.

Segundo Costa (2006), o conjunto de indicadores de avaliação de desempenho deve conter número reduzido de medidas, mas que sejam chaves para avaliar o cumprimento dos objetivos estratégicos e associado com os fatores críticos de sucesso. É conveniente eleger um número limitado de indicadores críticos dentro de cada uma das perspectivas, favorecendo o foco na visão estratégica pretendida. Para Rampersad (2004, p. 115), construir indicadores de desempenho significa estabelecer padrão para mensurar o progresso do objetivo estratégico, a fim de monitorar o desempenho.

Costa (2006) destaca que o BSC centraliza sua atenção na estratégia, na visão e não no controle operacional. Portanto, os indicadores são estabelecidos para que as pessoas conduzam seus trabalhos em direção a visão geral, à estratégia, como uma possibilidade de comunicar as necessidades dos clientes, traduzir a estratégia em ações, dar suporte à tomada de decisão. Os indicadores de mensuração devem avaliar a estratégia pretendida e não serem estipulados pela sua facilidade ou disponibilidade. Conforme as alterações ambientais da organização, os indicadores devem ser ajustados. 


\section{DIAGNÓSTICO E ANÁLISE DO MAPA ESTRATÉGICO DE UMA CORPORAÇÃO RELIGIOSA COM OBJETIVOS EDUCACIONAIS: ESTUDO DE CASO}

Duclós e Santana (2010, p. 46-47) aportam que os indicadores são informações necessárias para realizar as análises gerenciais, para medir a efetividades operacional e dar feedback sobre o desempenho estratégico da organização. Os indicadores geram informações do ponto de vista gerencial e estratégico, possibilitando vantagens competitivas, desde a minimização de riscos, a redução de custos, alavancagem do valor e, inovação. Os melhores resultados são evidenciados quando as informações acumuladas são agrupadas, conectadas e articuladas, gerando conhecimento organizacional por meio da ação das pessoas.

Os estudos de Furlan (2007, p. 88) demonstra a falta de motivação dos colaboradores para a implementação da estratégia definida, quando não se aplica uma política de recompensa clara, factível e balanceada entre os diversos requisitos. Rickli e Fernandes (2005, p. 105) enfatizam que a avaliação de desempenho e a meritocracia auxiliam o alcance dos objetivos individuais e da organização como um todo. Reforça o compromisso, as atitudes, o comportamento proativo dos indivíduos com a estratégia, no sentido de superar os desafios e contribuir para os resultados pretendidos.

Pereira (2004, p. 2) salienta que a organização sem fins lucrativos tem profissionalizado seu modelo de gestão, principalmente quanto ao desenvolvimento gerencial. Essa melhoria é visualizada pela implementação de indicadores que possibilitam processos de mudanças incrementais e revolucionárias. Tais indicadores não são estáticos, devem acompanham as alterações ambientais da organização.

Furlan (2007, p. 44) acrescenta que a vinculação dos ativos intangíveis com a estratégia e ao desempenho da organização é fundamental para o alinhamento interno, uma vez que os ativos intangíveis são fonte geradora de valor para os clientes. Essa conexão permite alinhar ativos à estratégia e mensurar sua contribuição, por meio de indicadores.

Duclós e Santana (2010, p. 153) diferenciam os indicadores de desempenho dos indicadores gerenciais. Os primeiros são estratégicos e os números de indicadores controlados tendem a ser reduzidos, com metas baseadas em benchmarking de mercado e estão intimamente ligados aos objetivos estratégicos. O segundo grupo de indicadores é incremental, em grande número, e as suas metas calculadas a partir de dados históricos. Quando um objetivo estratégico é retirado do mapa, o indicador de desempenho se transforma em indicador gerencial e vice-versa. 


\section{DIAGNÓSTICO E ANÁLISE DO MAPA ESTRATÉGICO DE UMA CORPORAÇÃO RELIGIOSA COM OBJETIVOS EDUCACIONAIS: ESTUDO DE CASO}

Segundo Duclós e Santana (2010, p. 152), existem dois tipos de indicadores de desempenho. Primeiro, os indicadores de tendência, que sinalizam resultados futuros a serem atingidos, em que o delineamento das metas levará ao alcance de outras metas relacionadas por causa-efeito, favorecendo aos gestores a tomada de decisão. Segundo, os indicadores de resultado, que evidenciam fatos que já ocorreram e que são comuns a diversos tipos de organizações.

Para Takashina e Flores (1996), os indicadores de resultado informam o desempenho somente em determinado período, são reativos, enquanto os indicadores de tendência são próativos, uma vez que se referem às variações dos níveis de resultados, permitindo que se estabeleça padrão de comparação.

Furlan (2007, p. 38) destaca que a relevância dos indicadores em ambientes complexos e mutantes, uma vez que os mesmos auxiliam no "estabelecimento da quantificação de um processo e estabelece padrões para que se possa avaliar o desempenho". Os indicadores favorecem as organizações a possibilidade de monitorar os processos internos e externos. Tal dinâmica propicia à observação do desempenho de cada processo e o conjunto da organização. Assim, os gestores identificaram onde devem focar energia para que se obtenha maior valor agregado na entrega do produto ou serviço. Cabem as organizações o empenho em analisar indicadores, que representem atividades, processos e perspectivas que percorrem em toda cadeia produtiva, a fim de identificar o desempenho efetivo.

Portanto, os indicadores de desempenho favorecem o controle estratégico, identificando se a tradução da estratégia pré-estabelecida está em curso e, favorece ainda o realinhamento estratégico em face dos desvios detectados, sugerem Kaplan e Norton (1997). Assim a função do controle estratégico é reorientar a organização, buscando entender e sanar a causa do problema ou do processo.

\section{PROCEDIMENTO METODOLÓGICO}

A metodologia científica que embasa o presente estudo é a pesquisa exploratória, qualitativa e descritiva. Segundo Gil (1994), a pesquisa exploratória tem como objetivo proporcionar maior familiaridade com a situação problema, explicitar ou construir proposições para estudos subsequentes. Kneller (1980) afirma que essas pesquisas têm como principal objetivo o aprimoramento de idéias ou a descoberta de intuições. Mattar (1996, p. 


\section{DIAGNÓSTICO E ANÁLISE DO MAPA ESTRATÉGICO DE UMA CORPORAÇÃO RELIGIOSA COM OBJETIVOS EDUCACIONAIS: ESTUDO DE CASO}

45) afirma ainda que a pesquisa exploratória "visa prover o pesquisador de um maior conhecimento sobre o tema ou problema de pesquisa".

As principais características da pesquisa qualitativa, segundo Bogdan apud Godoy (1995), são: i) o próprio ambiente é a fonte direta para a obtenção de dados, tendo o pesquisador como principal instrumento para extraí-los; ii) é descritiva; iii) pesquisadores utilizam a forma indutiva na análise de dados e; iv) os pesquisadores se concentram no processo tendo os resultados como conseqüência do estudo e não o seu principal foco. Corrobora Chizzotti (1991, p. 79) ao descrever que na abordagem qualitativa "o sujeito observador é parte integrante do processo de conhecimento e interpreta os fenômenos, atribuindo-lhes um significado".

Gil (1994) e Minayo (2001) dizem que a pesquisa descritiva busca, primordialmente, descrever e compreender as características de determinado fenômeno e estabelecer possíveis relações entre variáveis.

A pesquisa de campo será realizada por meio de um estudo de caso. De acordo com Yin (1994), o estudo de caso possibilita a investigação profunda e detalhada de uma ou mais organizações, com o objetivo de testar as questões de pesquisa construídas a partir de um referencial teórico. Yin (2005) destaca que o estudo de caso é utilizado quando o pesquisador tem pouco controle sobre os acontecimentos e quando o foco se encontra na investigação dos "fenômenos contemporâneos inseridos dentro de um contexto da vida real, especialmente quando os limites entre o fenômeno e o contexto não estão claramente definidos", em que a "observação direta dos acontecimentos que estão sendo estudados e entrevistas das pessoas neles envolvidos" (YIN, 2005, p. 32; 122).

Para o referido estudo empírico, é tomada como referência a Corporação Religiosa. O pesquisador mantém atuação na área estratégica da organização, com acesso as práticas, aos processos, as políticas, as estratégias, ou seja, pertence à gestão da organização. A escolha do tema da pesquisa ocorreu em virtude do pesquisador atuar na gestão da organização e acompanhar os processos da gestão estratégica, tendo o BSC como uma ferramenta que possibilita a organização alinhar, comunicar, acompanhar, monitorar e avaliar o desempenho organizacional.

A Corporação Religiosa mantém atuação no campo da educação superior, hospitalar, comunicação, solidariedade e outras atividades de suporte as anteriormente explicitadas. A 


\section{DIAGNÓSTICO E ANÁLISE DO MAPA ESTRATÉGICO DE UMA CORPORAÇÃO RELIGIOSA COM OBJETIVOS EDUCACIONAIS: ESTUDO DE CASO}

Corporação Religiosa tem apresentado índices do retorno sobre o Patrimônio Líquido de 14\%, em 2009 e 15\% em 2010. A EBITDA sobre a receita líquida foi de 10\%, em 2009 para 11\% em 2010, superior ao CDI do período correspondente a 9,88\% e 9,73\% respectivamente.

Com vistas ao delineamento do objeto de estudo e construção do marco teórico, foram realizadas pesquisas bibliográfica e documental. A pesquisa bibliográfica constitui etapa importante da pesquisa, por ser "um apanhado geral sobre os principais trabalhos já realizados, revestidos de importância por serem capazes de fornecer dados atuais e relevantes sobre o tema" (MARCONI e LAKATOS, 2002, p. 27). Minayo (1994) acrescenta que a pesquisa bibliográfica busca informações em documentos, livros, teses, dissertações, artigos, revistas, entre outros, que se relacionam com o problema de pesquisa.

Segundo Gil (2002, p. 73), a pesquisa documental utiliza documentos de primeira mão, que não receberam nenhum tratamento analítico, e os documentos de segunda mão, que de alguma maneira ganharam alguma análise e tratamento, tais como relatórios de gestão, procedimentos, pesquisas estudos anteriores sobre a organização. Utilizaram-se documentos internos da Corporação Religiosa, como planos, relatórios, livros, sites, registros eletrônicos.

A Corporação Religiosa é uma associação civil de direito privado, imune, filantrópica, com fins não econômicos, com o objetivo educacional. A Corporação Religiosa tem como finalidade estatutária promover o atendimento e o assessoramento, de fins educacionais, culturais, de comunicação social, de saúde, editoriais, e religiosos e de solidariedade. O Grupo Religioso tem atuação em todo território nacional e mais de 80 países, promovendo educação de qualidade, seja por meio da educação básica, técnica, profissionalizante e superior, assim como em áreas da saúde, da cultura, da comunicação, da solidariedade, dentre outras, de forma paga ou gratuita.

A Corporação Religiosa compreende cinco grandes frentes: educação superior, com mais de 33 mil alunos de graduação, especialização, mestrado e doutorado; saúde, composta por quatro hospitais e um plano de saúde; comunicação, detentora de três rádios e um canal de televisão; solidariedade, com realização de promoção e defesa de infâncias e juventudes e; negócios suplementares, conjunto de atividades e negócios demandados pelas áreas fins ou oportunidades que foram sendo agregadas ao longo dos anos, dentre outros.

A partir de 2005, a Corporação Religiosa assume papel de gestão das diversas unidades de negócio e entidades vinculadas por meio de alianças estratégicas. Até então, a gestão 


\section{DIAGNÓSTICO E ANÁLISE DO MAPA ESTRATÉGICO DE UMA CORPORAÇÃO RELIGIOSA COM OBJETIVOS EDUCACIONAIS: ESTUDO DE CASO}

estratégica e administrativa da Organização Religiosa eram alocada dentro e uma de suas unidades de negócio, que exercia os dois papéis. Fica evidente nos registros do presidente a necessidade de reposicionar a organização para melhor atender à sua missão - desenvolver e difundir o conhecimento e a cultura, promovendo a formação integral e permanente de pessoas comprometidas com a vida e com o desenvolvimento da sociedade. Atrelado ao crescimento, a diversificação e a maior complexidade, necessitando adaptar-se ao novo momento histórico.

A governança da organização passou a ter nova configuração e ao mesmo tempo se estabeleceu um planejamento estratégico da Corporação Religiosa. Na qual, o Conselho de Administração passou ter papel mais efetivo e estratégico.

No balanço de 2010, a Corporação Religiosa, considerando também suas alianças, contava com 6.891 colaboradores, dentre eles, 2.430 pertencentes a estrutura administrativa e suporte, 1.309 são docentes, 2.607 compõem a área hospitalar, 81 pertencem a área de comunicação, 327 são dos negócios suplementares e, 137 são da área de solidariedade.

Em 2010, a Corporação Religiosa desencadeou novo processo de planejamento estratégico, partindo da missão, da visão de futuro e dos valores. Extraiu os fatores críticos de sucesso e estabeleceu o Mapa Estratégico, sistematizado na Figura 1. A partir da referida sistematização, busca-se diagnosticar a coerência do Mapa Estratégico, nas quatro perspectivas do BSC, no ambiente corporativo.

A pesquisa foi realizada com dados de fontes secundárias e primárias. Para o incremento das fontes dos dados secundários foram utilizados os relatórios de atividade da Corporação Religiosa, os sistemas internos e outras publicações da organização, bem como consultas em artigos científicos, dissertações e teses.

Para as fontes de dados primários, foi utilizada a observação e a entrevista com questionário semiestruturado qualitativo, nos meses de junho e junho de 2011, elaborado a partir da revisão bibliográfica, incluindo os elementos mais significativos, dividido em seis categorias: balanceamento, alinhamento, relação causa efeito, comunicação da estratégia, indicadores de desempenho e gerenciamento da estratégia. O escopo do referido trabalho pretende diagnosticar e a coerência do Mapa Estratégico da Corporação Religiosa, nas quatro perspectivas do BSC, tendo como base o planejamento estratégico de 2010 a 2022 A amostra é não probabilística intencional, composta por cinco gestores da alta administração da 


\section{DIAGNÓSTICO E ANÁLISE DO MAPA ESTRATÉGICO DE UMA CORPORAÇÃO RELIGIOSA COM OBJETIVOS EDUCACIONAIS: ESTUDO DE CASO}

Corporação Religiosa. Segundo Richardson (1999), o entrevistador solicita a autorização do respondente para gravar a entrevista e providencia o termo de consentimento.

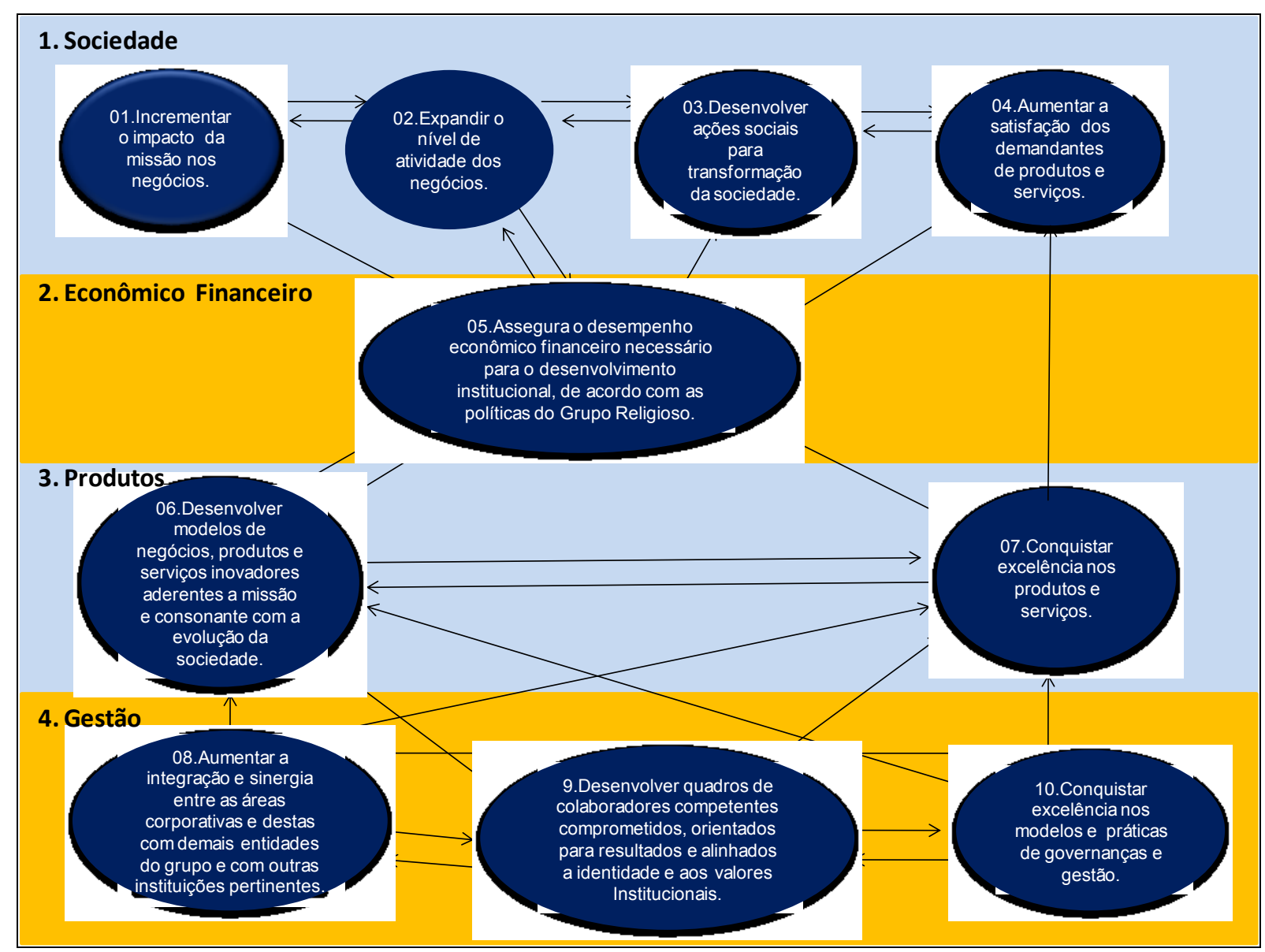

Figura 1 Mapa Estratégico da Corporação Religiosa.

Fonte: Planejamento Estratégico da Corporação Religiosa de 2010 a 2022, 2010.

As entrevistas semiestruturadas foram apoiadas num roteiro pré-estabelecido, construídos com base em autores que descrevem o BSC, de maneira especial Kaplan e Norton (1997, 2001, 2006), sobre Mapa Estratégico, ao abordar tradução e avaliação das estratégicas.

Segundo Beuren (2006), na amostra intencional o pesquisador precisa ter um conhecimento prévio da população, pois ele consiste na seção amostral com base nas informações já existentes e que sejam consideradas como representativas da população.

Os dados secundários foram analisados por meio da técnica de análise documental. Bardin (2009, p. 45) a define como "uma operação ou um conjunto de operações, visando representar o conteúdo de um documento sob uma forma diferente da original, a fim de facilitar, num estudo ulterior, a sua consulta e referenciação". Como dados secundários foram 
considerados os documentos referenciados neste trabalho e também os diversos documentos e relatórios da organização analisada.

Segundo Richardson (1999), o delineamento de estudo de caso único, a pesquisa exploratória e qualitativa apresenta algumas circunscrições quanto à generalização do mesmo, mas também possibilita a oportunidade de apresentar um estudo diferenciado.

\section{ANÁLISE DOS RESULTADOS}

A análise dos resultados é apresentada de maneira descritiva a partir das seis categorias construídas na formulação da pesquisa exploratória, sempre com foco no Mapa Estratégico 2010 a 2022, vigente na Corporação Religiosa, apresentado na Figura 1. Os elementos são: balanceamento, alinhamento relação causa efeito, comunicação da estratégia, indicadores de desempenho e gerenciamento da estratégia.

Para alguns gestores, o balanceamento do Mapa Estratégico contempla à quantidade de objetivos distribuída nas quatro perspectivas, uma vez que os objetivos consideram e expressam a missão, a visão e a orientação estratégica da Corporação Religiosa. Mas destacam também que falta aprofundar a integração entre aspectos do carisma e do negócio. Outros gestores identificam que os objetivos são excessivamente genéricos, o que facilita uma interpretação ampla, mas dificulta um entendimento equânime, sejam referentes os elementos técnicos como os carismáticos.

É unanime para alta administração, como para Kaplan e Norton (1997), que o atual posicionamento das perspectivas, está mais coerente com uma organização com fins não econômicos, educacional e religiosa, colocando no topo a sociedade/clientes, a qual vai ao encontro da visão e missão da mesma. Alguns salientam que até recentemente predominava a perspectiva econômico-financeira, devido à situação adversa que enfrentava nesta dimensão. Mas ainda a organização está aprendendo a colocar na agenda estratégica o novo enfoque.

Segundo os gestores, o Grupo Religioso desdobra as estratégias para a Corporação Religiosa, e esta diverge quanto ao alinhado do Mapa Estratégico com as unidades de negócio, destas com as áreas de apoio e, por fim, entre as próprias áreas de apoio da Corporação. Alguns destacam que o alinhamento é perceptivo e há um esforço gradativo do conselho de administração e dos gestores em tomar decisões e ajustar processos, estruturas e tecnologias que propiciam maior conectividade e sinergia entre os níveis organizacionais. 


\section{DIAGNÓSTICO E ANÁLISE DO MAPA ESTRATÉGICO DE UMA CORPORAÇÃO RELIGIOSA COM OBJETIVOS EDUCACIONAIS: ESTUDO DE CASO}

Outros salientam que há mais resistência e dificuldade de integração entre Corporação Religiosa e unidades de negócios, uma vez que o alinhamento foi frouxamente acordado, dificultando a co-responsabilização, sejam por motivos históricos e culturais, demandas operacionais, conflitos de poder, excessiva burocracia, morosidade na tomada de decisão, baixo nível de autonomia, excessiva departamentalização e relatórios gerenciais de baixa relevância.

Os gestores ainda apontam que o processo de alinhamento entre os próprios departamentos da área de apoio da Corporação Religiosa possuem pouca aderência, cada qual atua em seu nicho e presta contas de seu conjunto de iniciativas e de tarefas. Poucos projetos são de fato pensados e executados de maneira sistêmica, envolvendo organicamente as diferentes frentes. Outra preocupação latente é a dificuldade tanto das áreas de apoio, como das unidades de negócio em centrar esforços nos processos e estratégias do cliente.

Atualmente, o que tem favorecido mais o alinhamento parece não ser a estrutura, mas o planejamento estratégico, o orçamento e a meritocracia, apesar dos gestores demonstrarem que tais elementos patrocinam um horizonte meramente de curto prazo. Outros defendem que a estrutura não parece equivocada, mas sim é mandatório rever processos, favorecer maior grau de autonomia, pautado em alçadas, delegar e responsabilizar níveis mais intermediários.

O Mapa Estratégico parece não comunicar claramente a relação de causa-efeito e suas concatenações. É perceptível na Figura 1 pela quantidade de setas apresentado no Mapa. O que pode provocar falta de nitidez dos vetores chaves que influenciam e são influenciados, afetando as próprias opções estratégicas traçadas pelos gestores. Segundo Duclós e Santana (2010), a relação causal contribuir para evidenciar os objetivos estratégicos distribuídos nas diversas perspectivas.

Há consenso de que o Mapa Estratégico traduz e comunica a missão, a visão e as estratégias do Grupo Religioso. Porém, os gestores da alta administração demonstram dar poucas evidências de como ela é de fato comunicada nos diversos níveis da organização, seja entre as áreas de apoio da Corporação Religiosa ou desta para suas unidades de negócio. Aparenta que os gestores trabalham de maneira fragmentada, apresentando nível de desempenho satisfatório quando analisado por departamentos. Apesar de que, mesmo dentro de cada área, os processos de apropriação do Mapa, das iniciativas e dos projetos deles 


\section{DIAGNÓSTICO E ANÁLISE DO MAPA ESTRATÉGICO DE UMA CORPORAÇÃO RELIGIOSA COM OBJETIVOS EDUCACIONAIS: ESTUDO DE CASO}

decorrentes, são poucos tratados, transparecendo mais uma vez, uma comunicação hierarquizada.

Os níveis mais estratégicos demonstram conhecimento das estratégias da Corporação Religiosa, mas estes confirmam que o processo de comunicação para níveis mais intermediários é quase inexistente. Por fim, alguns gestores destacam que utilizam pouco o Mapa Estratégico, se debruçam mais nas orientações estratégicas, que trata de uma visão "desenvolvimentista, balizada pela expansão dos negócios e da missão, sustentabilidade, excelência, inovação, integração e incidência política" (PLANEJAMENTO ESTRATÉGICO DA CORPORAÇÃO RELIGIOSA, 2010).

Segundo Kaplan e Norton (2004, p. 41), o Mapa Estratégico traduz a estratégia por meio de um conjunto de indicadores para mensurar o desempenho conseguido em cada um dos objetivos distribuído nas quatro perspectivas. Dê um lado, é unanime para a alta administração que não há indicadores de desempenho explicitados e acordados para os objetivos estratégicos desenhados no Mapa, o que dificulta o entendimento de que rumo à organização pretende percorrer e consequentemente sua comunicação fica prejudicada.

Por outro, cada área da Corporação Religiosa tem estabelecido diversas parametrizações objetivas, ligada as iniciativas e aos projetos estratégicos, capazes de mensurar e avaliar resultado, tendências e percepção, tanto de aspectos tangíveis como intangíveis, mas com abrangência de curto prazo. Alguns exemplos de indicadores utilizados pelas diversas áreas: clima organizacional, ticket médio por aluno, margem bruta, margem por curso, avaliações do MEC para a instituição e para os cursos, EBITDA, retorno sobre investimento, avaliação dos docentes e discentes, evolução do número de alunos pagantes ou não, aumento da utilização da capacidade, aumento de especialistas, mestres e doutores, redução do turnover dos colaboradores, captação de recursos, entre outros.

Fica claro que há alguns indicadores comuns bastaria a Corporação Religiosa estabelecer um balizador ou meta padronizada para cada área, como é o caso do orçamento, desempenho e clima organizacional. Mas em sua grande maioria os indicadores e metas estabelecidos estão atrelados mais as iniciativas do planejamento estratégico do que aos objetivos do Mapa. É demonstrado pelos gestores que os objetivos do Mapa Estratégico, descritos na Figura 1, são demasiadamente genéricos, o que dificulta o estabelecimento dos indicadores de desempenho tangíveis e intangíveis, de retorno e de resultado. 
A alta administração explicita que a organização utiliza a meritocracia para inserir alguns indicadores de desempenho, corrobora com o pensamento de Rickli e Fernandes (2005) e de Furlan (2007) sobre a política de recompensa clara, factível e balanceada. A meritocracia perpassa as quatro perspectivas, de maneira não equilibrada, apesar de estabelecer uma diferenciação dos itens a serem mensurados para cada unidade de negócio e área de apoio. Ficam mais evidentes indicadores de clima organizacional, o cumprimento das metas orçamentárias e de resultado financeiro. Os gestores admitem haver um acompanhamento com feedbacks periódicos quanto às metas acordadas, seja pessoalmente ou via sistema eletrônico de gestão.

Alguns gestores apontam que as metas estipuladas na meritocracia são demasiadamente subjetivas, dificultando a real aferição, ou ainda apresentam indicadores binários (sim ou não) impedindo a qualificação escalonada do objeto em avaliação.

Os gestores da alta administração destacam que a organização tem demonstrado profissionalismo, governança e aprendizado organizacional. O momento é propício para estabelecer indicadores de desempenho para a Corporação Religiosa, mesmo que necessite diferenciar a mensuração devido às peculiaridades de cada unidade de negócio.

Um conjunto de gestores acredita que o Mapa Estratégico auxilia no gerenciamento da estratégia de maneira a canalizar e direcionar as competências e os investimentos da organização. Ainda colabora na eficácia e eficiência do processo de gestão. Outro grupo aponta a baixa fluidez da comunicação estratégica e salientam a necessidade de dar mais clareza e objetividade as estratégias. A visão sistêmica dos gestores com relação a estratégica fica prejudicada, uma vez que o olhar operacional é evidenciado pela excessiva departamentalização.

O desempenho da Corporação Religiosa tem melhorado significativamente desde o início da utilização do planejamento, do mapa estratégico e dos indicadores, do desenvolvimento das boas práticas de gestão, da organização dos processos internos, da avaliação do clima organizacional e para o direcionamento e posicionamento da organização.

\section{CONSIDERAÇÕES FINAIS}

Para os gestores da área de apoio da Corporação Religiosa o Mapa Estratégico é genérico, tem pouca relação de causa-efeito e a comunicação da estratégia não parece ser 
clara, mas possui um balanceamento e alinhamento com a missão e visão da organização. Há baixo grau de autonomia e responsabilização ao desdobrar o Mapa Estratégico para as próprias áreas de apoio e unidades de negócio, atua de maneira fragmentada e departamentalizada com visão de curto prazo.

A Corporação Religiosa possui indicadores de desempenho no âmbito das iniciativas, de curto prazo, ligados essencialmente a meritocracia, apresentando evidências de serem mais tangíveis e de resultados. Os objetivos do Mapa Estratégico da organização não são traduzidos em indicadores de desempenho objetivados e comunicados para favorecer a estratégia da Corporação e do Grupo Religioso.

Segundo a alta administração, com a melhora da governança e com o gerenciamento da estratégia tem aprimorado a aprendizagem e o desempenho da Corporação Religiosa, favorecendo a mesma a elevar seu nível de competitividade no contexto contemporâneo.

\section{REFERÊNCIAS}

ANDREWS, K. R. Concepto de estrategia de la empresa. Barcelona: Navarra, 1971.

AVANCINI, M. A peso de outro. REVISTA EDUCAÇÃO Edição 164, dez. 2010. Disponível em: $<\mathrm{http}: / /$ revistaeducacao.uol.com.br/textos.asp? codigo=13041>. Acesso em: 06 fev. 2011.

BARDIN, L. Análise de conteúdo. Edição revista e atualizada. Lisboa: Edições 70, 2009.

BESANKO, D. et all. A Economia da Estratégia. Porto Alegre: Bookman, 2006.

BEUREN, I. M. (Org.) Como elaborar trabalhos monográficos em contabilidade. São Paulo: Atlas, 2006.

CAIUBY, R. D.; LUCIANO, D. M. Vinculando estratégia aos processos operacionais. In.: KALLÁS, D.; COUTINHO, A. R. Gestão da estratégia: experiências e lições de empresas brasileiras. Rio de Janeiro: Elsevier, 2005.

CHIZZOTTI, A. Pesquisa em ciências humanas e sociais. São Paulo, Cortez, 1991.

COSTA, A. P. P. Balanced Scorecard. Conceitos e guia de implementação. Editora Atlas: São Paulo, 2006.

DUCLÓS, L. C. e SANTANA, V. L. Ciclo Estratégico da Informação: como colocar a TI no seu devido lugar. Ed. Champagnat: Curitiba, 2010. 
FURLAN, G. A. Contribuição do Balanced Scorecard para a Construção do Mapa Estratégico de Instituições Educacionais Sem Fins Lucrativos. Dissertação de Mestrado. Administração, Instituição Municipal de Ensino Superior de São Caetano do Sul, São Caetano do Sul, 2007.

GIL, A. C. Como elaborar Projetos de Pesquisa. São Paulo: Atlas, 2002.

GIL, A. C. Métodos e técnicas de pesquisa social. São Paulo: Atlas, 1994.

GODOY, A. S. Introdução à pesquisa qualitativa e suas possibilidades. Revista de Administração de Empresas, Rio de Janeiro, v.35, n.2, p.57-63, abr./mar. 1995.

HOFER, C. W. \& SCHENDEL, D. Business Policy and Strategic Management. Strategy formulation: Analytical concepts. West Publishing Company, 1978.

JÚNIOR, V. H. História dos 50 anos da Pontifícia Universidade Católica do Paraná 1959/ 2009. Curitiba: Ed. Champagnat. 2009.

KALLÁS, D.; COUTINHO, A. R. Gestão da estratégia: experiências e lições de empresas brasileiras. Rio de Janeiro: Elsevier, 2005.

KAPLAN, S. R., NORTON, P. D. Balanced Scorecard: A Estratégia em Ação. Rio de Janeiro: Campus, 1997.

KAPLAN, S. R., NORTON, P. D. Balanced Scorecard: Mapas estratégicos, convertendo ativos intangíveis em resultados tangíveis. Rio de Janeiro: Campus, 2004.

KAPLAN, S. R., NORTON, P. D. Organização Orientada para a Estratégia- The Strategic-Focused Organization, Rio de Janeiro, Campus , 2001.

KNELLER, G. F. A Ciência como atividade humana. Rio de Janeiro: Zahar, 1980.

MARCONI, M. A.; LAKATOS, E. M. Técnicas de pesquisa. 5. ed. São Paulo: Atlas, 2002.

MATTAR, F. N. Pesquisa de Marketing. 3.ed. São Paulo: Atlas,1996.

MINAYO, M. C. S. (Org). Pesquisa Social: teoria, método e criatividade. Petrópolis, RJ: Vozes, 1994.

MINTZBERG, H.; QUINN, J. B. The Strategy Process: Concepts, Contexts and Cases. Englewood Cliffs: Prentice-Hall International, 1991.

PEREIRA, F. E. O Balanced Scorecard na gestão de organizações sem fins lucrativos: estudo de caso no SENAC/SC. Dissertação de Mestrado. Engenharia de Produção e Sistemas, Universidade Federal de Santa Catarina, Florianópolis, setembro de 2004.

PLANEJAMENTO ESTRATÉGICO DA CORPORAÇÃO RELIGIOSA 2010 a 2022, 2010.

Rev. GUAL., Florianópolis, v.4, n. 2, p.182-204, mai/ago. 2011 
PORTER, M. E. Competição: estratégias competitivas essenciais. Rio de Janeiro: Campus, 1999.

RAMPERSAD, H. K. Scorecard para performance total. São Paulo: Elsevier, 2004.

RICHARDSON, R. J. Pesquisa Social: métodos e técnicas. São Paulo: Atlas, 1999.

RICKLI, A.; FERNANDES, M. A. Compromisso das pessoas com a estratégia. In.: KALLÁS, D.; COUTINHO, A. R. Gestão da estratégia: experiências e lições de empresas brasileiras. Rio de Janeiro: Elsevier, 2005.

ROCHA, D. J. A.. Desenvolvimento do Balanced Scorecard para instituição de ensino superior privada: estudo de caso da unidade de negócios quatro da Universidade Gama. Dissertação de Mestrado em Engenharia da Produção. Universidade Federal de Santa Catarina UFSC, Florianópolis, 2000.

SENGE, P. M. A quinta disciplina. São Paulo: Editora Best Seller, 1990.

TAKASHINA, N. T.; FLORES, M. C. X. Indicadores da qualidade e do desempenho: como estabelecer metas e medir resultados. Rio de Janeiro: Qualitymark, 1996.

VIEIRA, D. Capital Estrangeiro na Educação Brasileira. Quem paga a conta? REVISTA DO ENSINO SUPERIOR. Edição 109, nov. 2007. Disponível em: $<$ www.revistaensinosuperior.com.br>. Acesso em: 12 fev. 2011.

WRIGHT, P.; KROLL, M.; PARNELL, L. Administração estratégica: conceitos. São Paulo: Atlas, 2000.

YIN, R. K. Estudo de caso: Planejamento e métodos. 3. ed. Porto Alegre: Bookman, 2005. 


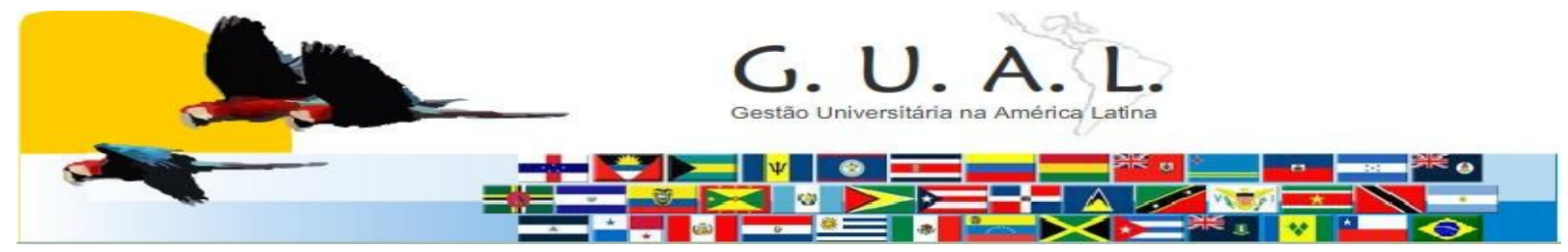

ISSN 1983-4535

\title{
DIAGNOSIS AND ANALYSIS OF THE STRATEGIC MAP OF A RELIGIOUS CORPORATION WITH EDUCATIONAL OBJECTIVES: A CASE STUDY
}

\author{
Jorge Gaio, Mestre, Bacharel \\ Pontifícia Universidade Católica do Paraná-PUC/PR \\ irjorge@marista.org.br \\ Luiz Carlos Duclós, Doutor \\ Pontifícia Universidade Católica do Paraná - PUC/PR \\ luiz.duclos@pucpr.br
}

\begin{abstract}
International educational corporations have expanded their operations in the national arena, pressuring national organizations to improve their performance strategies and structure. The objective of this qualitative, descriptive and exploratory case study is to identify the Strategic Map coherence in an non profitable educational religious corporation in the four perspectives of the Balanced Scorecard - BSC, based on its 2010 - 2022 strategic planning. A review of the literature cove was made to the main aspects of the BSC and strategy. The BSC is an important alignment tool for processes and strategies, to the extent that it associates specific performance drivers with measurement of results. Using the Religious Corporation Strategic Map, it was diagnosed its consistency at the strategic level of the organization and if the translation of the strategy and the indicators are noticed by corporate managers in their area, using a questionnaire in semi-structured interviews. The results indicate balanced and aligned strategic objectives, low causal relationship map, insufficient and fragmented strategic communication. The performance indicators are linked more with meritocracy than with the strategic map which given more important a short-term vision over the long term. There is evidence of improved management and strategic performance.
\end{abstract}

Keywords: Religious Corporation, Strategy Map, Performance of Indicators. 